\title{
A legalidade do parecer médico-veterinário
}

\section{The legality of veterinary expert reports}

\section{Resumo}

O aumento do número de ações na justiça e processos éticos contra médicos-veterinários e a busca não só por reparações indenizatórias, mas também laudos técnicos tem tido significativa demanda. Qual é o valor legal de um parecer técnico quando a ação ainda não foi impetrada na justiça por quem tem o objetivo de fazê-la, ou seja, quando há incerteza se a ação será de fato levada adiante? O novo Código de Ética Médica-veterinária Brasileiro, que entrou em vigor no dia 9 de setembro de 2017, não cita o uso desse instrumento por parte do médico-veterinário, com o intuito de corroborá-lo judicialmente. Já o novo Código de Processo Civil (lei federal brasileira), de 2015, que revogou o texto anterior, manteve a previsão legal do uso do parecer técnico de profissional, contratado ou não, como assistente técnico por uma das partes para endossar ou discordar do laudo de um perito ou apenas fundamentar as alegações das partes num processo judicial. Em vista disso, este ensaio promove reflexão e elucida a dúvida que paira sobre os profissionais que são requisitados para a elaboração de um documento que poderá ou deverá ter valor jurídico quando o proprietário de um animal pensa em acionar um médico-veterinário, seja civil ou eticamente.

\section{Abstract}

The demand for lawsuits and ethical proceedings against veterinarians, seeking compensation as well as technical reports, has been significantly increasing. What is the legal value of a technical opinion when the action has not yet been initialized in court? The Brazilian "New Code of Veterinary Medical Ethics", which came into force on September 9, 2017, does not mention the use of this instrument by veterinarians, with the purpose of legally corroborating them. The New Code of Civil Procedure (Brazilian Federal Law) of 2015, which repealed the previous text, maintained the legal provision for the use of the technical opinion of a professional, contracted or not as a technical assistant by one of the parties, to endorse or disagree with the expert's report, or only to substantiate the parties' claims in a judicial proceeding. Therefore, this essay suggests a reflection with the aim of elucidating doubts about the preparation of a document that may or should have a legal status when an animal's owner prosecutes a veterinarian, civilly or ethically. 
Clifton Davis da Cruz Conceição

Christian John da Cruz Conceição²

Elaine Cristina de Freitas Oliveira ${ }^{3}$

Martha Christina Mariotti Claro 4

Tália Missen Tremori ${ }^{5}$
Rua Padre Manuel Barbosa, 134,

Bloco A, apto. 1202,

Itaigara, Salvador/BA, Brasil

CEP: 41815-050

هcdccvet@yahoo.com.br

\section{Palavras-chave}

Perito judicial. Responsabilidade profissional.

Perícia veterinária.

\section{Keywords}

Legal expert. Professional liability.

Veterinary expertise.

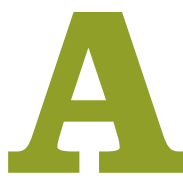

perícia veterinária é uma atividade privativa do profissional médico-veterinário, de acordo com a Lei 5.517, de 23 de outubro de 1968, que regulamenta o exercício da profissão de médico-veterinário no Brasil; nela, é citado que o exame pericial sobre animais, identificação, vícios redibitórios, doenças, acidentes e exames técnicos em questões judiciais são encargos do médico-veterinário (BRASIL, 1968).

Sabe-se que a interação da sociedade com os animais, desde os primórdios, é vê-los como companhia, produção e equilíbrio do ecossistema. Nesse contexto, deve ser considerada a evolução das legislações ao longo do tempo, inclusive as leis de proteção animal que estabelecem sanções penais e administrativas para aqueles que cometem crimes contra esses seres (TREMORI; ROCHA, 2013). O artigo $32 \mathrm{da}$ Lei de Crimes Ambientais (BRASIL, 1998) estabelece que "praticar ato

1 Médico-veterinário formado pela Unigranrio. Especialização em Medicina Veterinária Legal pelo Inbrapec, São Paulo. Perito Judicial no Estado do Rio de Janeiro. Membro da Comissão de Ensino da ABMVL.

2 Advogado formado pela PUC-RJ. Especialização em Advocacia Cível pela FGV.

3 Médica-veterinária formada pela UFRRJ. Mestranda da EMVZ, UFBA, Salvador.

${ }^{4}$ Advogada, formada pela Faculdade Brasileira de Ciências Jurídicas, Rio de Janeiro/RJ, Brasil. Pós-graduação em Direito Público pela FGV

${ }^{5}$ Médica-veterinária formada pela FMVZ Unesp-Botucatu. Mestrado em Patologia Animal pela FMVZ Unesp-Botucatu. Doutoranda da FMVZ Unesp-Botucatu, e Universidad de Salamanca, Espanha. Membro da Comissão Técnica de Medicina Veterinária Legal do CRMV-SP. 
de abuso, maus-tratos, ferir ou mutilar animais silvestres, domésticos ou domesticados, nativos ou exóticos é crime e tem como pena a detenção de três meses a um ano, além da multa".

Além disso, a fiscalização da atuação profissional daqueles que exercem atividades voltadas ao meio animal, no Brasil, se encontra normatizada pelos conselhos de classe nos âmbitos federal e estadual (MASSAD; MASSAD, 2017).

$\mathrm{O}$ aumento no número de processos envolvendo animais reflete na crescente demanda por profissionais com conhecimentos técnicos específicos e capacitados para atuarem como auxiliares da justiça, além daqueles com formação adequada para prevenir e evitar situações nas quais o médico-veterinário pode inclusive se tornar réu de um caso. Alegar desconhecimento das leis é intolerável - portanto, a capacitação é essencial. Nesse condão entra a prova pericial, que é fundamental em diversas situações processuais (CONCEIÇÃO; ALMEIDA; MARCON, 2017; SLOWINSKI et al., 2016). No dia 9 de setembro de 2017, o Conselho Federal de Medicina Veterinária (CFMV) do Brasil publicou a Resolução $\mathrm{n}^{\circ} 1.138$, de 16 de dezembro de 2016 - nada mais, nada menos que o Novo Código de Ética Médica-veterinária (CEMV), cujo art. $7^{\circ}$, inciso IV estabelece ser direito do médico-veterinário "prescrever, tratamento que considere mais indicado, bem como utilizar os recursos humanos e materiais que julgar necessários ao desempenho de suas atividades" (BRASIL, 2017). No entanto, a redação desse artigo não livra o profissional de sofrer ação na justiça.

Processos (civis e éticos) contra médicos-veterinários estão crescendo e isso já é sabido no meio. Vem sendo buscado, e muito, perante o Poder Judiciário responsabilizar os profissionais, de forma subjetiva ou objetiva, quando causam algum dano ao paciente (PAZÓ; HEANCIO, 2014).

\section{Objetivo}

Promover reflexão e elucidar a dúvida que paira sobre os profissionais que são requisitados para elaboração de um documento que poderá ou deverá ter conotação jurídica quando o proprietário de animal pensa em acionar um médico-veterinário perante a justiça.

\section{Parecer técnico veterinário}

Ainda que um possível erro médico-veterinário só possa ser confirmado por meio de perícia - ou seja, que somente um perito da justiça, nomeado por magistrado, tenha prerrogativa de apresentar laudo estabelecendo a existência de nexo de causalidade, um dos pressupostos da responsabilidade civil -, constata-se também, na prática, o aumento no número de proprietários de animais recorrendo a alguns colegas para que seja emitido um parecer sobre eventuais intercorrências ocorridas durante a prestação de serviço médico-veterinário.

Este ensaio não tem a pretensão de debater o ofício de um parecerista, que é o profissional responsável pela formulação de pareceres, opiniões especializadas sobre algo (PARECERISTA, 2011), mas de chamar a atenção para os serviços de consultoria pericial que alguns médicos- veterinários oferecem - seja por meio de sites, cartões de visita ou redes sociais -, que incluem, entre outros, o da elaboração de pareceres técnicos.

De acordo com o novo Código de Processo Civil (CPC) brasileiro, quem emite laudo pericial é o perito e quem digita um parecer técnico é o assistente técnico contratado por uma das partes para fundamentar sua defesa dentro de um processo judicial; cf. o art. 470 , II, $₫ 2^{\circ}$ : “O perito e os assistentes técnicos devem entregar, respectivamente laudo e pareceres em prazo fixado pelo juiz" (BRASIL, 2015, p. 159).

O novo CPC diz ainda, no art. 472, que "o juiz poderá dispensar prova pericial quando as partes, na inicial e na contestação, apresentarem, sobre as questões de fato, pareceres técnicos ou documentos elucidativos que considerar suficientes" (BRASIL, 2015, p. 159).

Sobre esse artigo, Castilho (2017, p. 48) discorre:

é comum médicos veterinários serem consultados pelas partes, para elaborarem pareceres técnicos que, se bem fundamentados, são suficientes para a tomada de decisão do juiz, o qual dispensa a prova pericial. Todavia, se o parecer não for suficientemente esclarecedor, o juiz pode nomear o perito e o signatário do parecer emitido, pode ou não, ser indicado como assistente nos autos. Esta condição dependerá da confiança inspirada na parte que o contratou e não do juiz.

\section{Legalidade do parecer}

Mas é legal e ética a redação de um documento que aponte falhas ou defenda um ponto de vista sobre a conduta profissional de um colega?

De acordo com o novo CEMV, não é autorizado a qualquer médico-veterinário comentar livremente, de forma depreciativa, a atuação de um profissional da Medicina Veterinária, segundo um dos incisos do art. 10 do capítulo VI, "Da Relação com outros médicos veterinários". “É vedado ao médico-veterinário: VI - fazer comentários desabonadores sobre a conduta profissional ou pessoal de colega" (BRASIL, 2017). 
Abordando mais um artigo do referido código normatizador do médico-veterinário, o art. 8 do capítulo IV, "Do comportamento", reforça o dito anteriormente: "É vedado ao médico-veterinário: XXVI - criticar trabalhos profissionais ou serviços de colegas sem fundamentação científica" (BRASIL, 2017).

Se houver "fundamentação científica" é permitido? O código de ética é omisso quanto a essa questão. Porém, entende-se, combinando os já citados arts. - e, em se tratando de processo ético, entendendo que não se pode fazer comentário desabonador -, que o médico-veterinário também não pode criticar trabalho profissional ou serviço de outro, ainda que com base em literatura médica-veterinária.

Inclusive, de acordo com o art. 6, inciso VIII do CEMV (BRASIL, 2017), devem ser denunciados quaisquer atos realizados sem observância dos preceitos éticos e procedimentos adequados. Esse artigo também se refere à atuação pericial.

Assim sendo, o CEMV, resolução que contempla os direitos e deveres dos profissionais, não os respalda a ressaltarem negativamente um ato médico-veterinário de outro profissional em nenhuma hipótese, nem de forma falada (comentar), nem por escrito. Isso configuraria, então, uma infração ética, sujeita a sanções administrativas impostas pelo Conselho Regional de Medicina Veterinária de onde foi cometida a irregularidade.

Pois bem: hierarquicamente, ou seja, segundo a Pirâmide de Kelsen (Figura 1), tão ensinada nos cursos de Direito, uma resolução é classificada e está localizada abaixo do CPC, que é lei federal (lei ordinária) - tem, portanto, menor peso jurídico.
Assim, por pertencerem a distintas esferas, não cabe o "confronto" entre os dois códigos, prevalecendo, sim, o que consta na norma classificada como a de maior "valor jurídico", que é o que está descrito no novo CPC.

Não que estejamos concordando com as críticas, fundamentadas ou não, entre médicos-veterinários. No entanto, ainda que possa parecer antiético perante o novo CEMV, há amparo legal, pelo CPC, para a análise de um médico-veterinário sobre a atuação de um colega com vistas a uma eventual acusação de irresponsabilidade profissional, tudo dentro de contexto processual, a fim de colaborar o Poder Judiciário.

Contudo, não é conveniente que um profissional que não esteja inserido num processo na justiça, especificamente indicado pelas partes como "perito assistente" (que é o caso do assistente técnico), ou que não tenha sido consultado para a emissão de um parecer por parte interessada venha deliberadamente opinar sobre ato alheio, principalmente por outros meios (como redes sociais) que não as vias judiciais. Ele pode sofrer ação tanto pela justiça comum (danos morais) quanto por processo ético, visto que, como já abordado, o código de ética não resguarda o médico-veterinário que concorda em criticar o ofício de outro profissional da classe.

Observa-se, entretanto, que não há qualquer impedimento ético ou legal para que o médico-veterinário que esteja fora ou até mesmo dentro de uma ação judicial elabore documento indicando acertos ou elogiando a postura e o trabalho de profissional da classe. O que inclusive, é muito comum dentro dos cadernos processuais em que são anexados depoimentos em favor de médicos-veterinários, elaborados por donos de animais ou colegas de profissão.

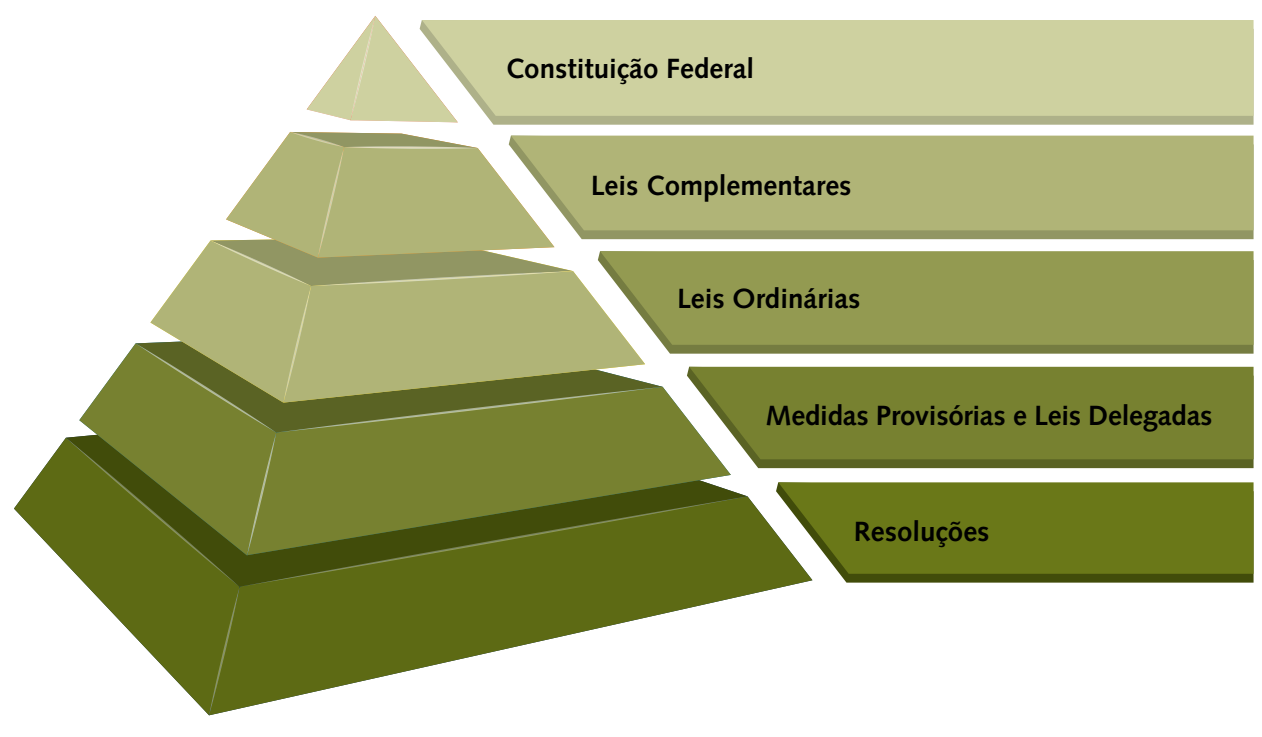

Figura 1 - Representação da Pirâmide de Kelsen. Fonte: Adaptado de Poggetti (2015). 


\section{Considerações finais}

Enfim, cumpre ser ratificado que um parecer técnico, redigido por profissionais contratados como assistentes técnicos (cujo nome consta num processo), ou um parecer anexado aos autos pelas partes, após consulta a um profissional, ainda que não seja indicado como assistente técnico, é previsto em lei.

Conclui-se, então, que é permitido, sobretudo em face do CPC, que um médico-veterinário emita parecer sobre a atividade profissional de terceiro.

\section{Referências}

BRASIL. Lei no 5.517, de 23 de outubro de 1968. Dispõe sobre o exercício da profissão de médico-veterinário e cria os Conselhos Federal e Regionais de Medicina Veterinária. Diário Oficial da União, Brasília, DF, 25 out. 1968. Disponível em: <https://bit. ly/2PhkVBd>. Acesso em: 22 nov. 2017.

BRASIL. Lei no 9.605, de 12 de fevereiro de 1998. Dispõe sobre as sanções penais e administrativas derivadas de condutas e atividades lesivas ao meio ambiente, e dá outras providências. Diário Oficial da União, Brasília, DF, 13 fev. 1998. Disponível em: <https://bit.ly/1La6hQT>. Acesso em: 22 nov. 2017.

BRASIL. Código de Processo Civil. São Paulo: Saraiva, 2015.

BRASIL. Conselho Federal de Medicina Veterinária. Resolução $\mathrm{n}^{\circ} 1.138$, de 16 de dezembro de 2016. Aprova o Código de Ética do Médico-veterinário. Diário Oficial da União, Brasília, DF, 25 jan. 2017. Disponível em: <https://bit.ly/2F6C38c>. Acesso em: 21 mar. 2018.
CASTILHO, V. V. Atuação do perito em Medicina Veterinária. In: TOSTES, R. A.; REIS, S. T. J.; CASTILHO, V. V. Tratado de Medicina Veterinária legal. Curitiba: Medvep, 2017. p. 41-86.

CONCEIÇÃO, C. D. C.; ALMEIDA, E. C. P.; MARCON, F. M. Novo Código de Ética Médica-veterinária: comentários sob a ótica pericial. [S.I.]: Escola Veterinária, 2017. v. 1.

MASSAD, M. R. R.; MASSAD, J. M. Responsabilidade profissional. In: TOSTES, R. A.; REIS, S. T. J.; CASTILHO, V. V. Tratado de Medicina Veterinária legal. Curitiba: Medvep, 2017. p. 107-118.

PARECERISTA. Dicio: Dicionário Online de Português, Matosinhos, 10 jan. 2011. Disponível em: <https://bit.ly/2D67GvS>. Acesso em: 2 nov. 2017.

PAZÓ, C. G.; HEANCIO, S. F. Responsabilidade civil do médico-veterinário: uma análise à luz do código de ética do médico-veterinário. Revista do Instituto do Direito Brasileiro, Lisboa, v. 3, n. 3, p. 2129-2156, 2014. Disponível em <https://bit.ly/2Dseu8e>. Acesso em: 6 nov. 2017.

POGGETTI, D. Relembrando a Pirâmide de Kelsen: parte 01. Équilibré Cursos e Treinamentos, [S.I.], 20 set. 2015. Disponível em: <https://bit.ly/2ARjVe6>. Acesso em: 20 nov. 2017.

SLOWINSKI, K. et al. Responsabilidade ética e civil do médico- veterinário no ambiente hospitalar. Revista de Educação Continuada em Medicina Veterinária e Zootecnia do CRMV-SP, São Paulo, v. 14, n. 2, p. 30-37, 2016.

TREMORI, T. M.; ROCHA, N. S. Exame do corpo de delito na perícia veterinária. Revista de Educação Continuada em Medicina Veterinária e Zootecnia do CRMV-SP, São Paulo, v. 11, n. 3, p. 30-35, 2013. 